\title{
Assessing Group Incentives, Independent Spending, and Campaign Finance Law by Comparing the States
}

\author{
Charles R. Hunt, Jaclyn J. Kettler, Michael J. Malbin, Brendan Glavin, and Keith E. Hamm
}

\begin{abstract}
Independent expenditures (IEs) in U.S. elections have increased substantially at nearly all levels of government over the past decade, but judicial decisions are only a partial explanation for this growth. Using a descriptive difference-in-differences approach, we show that the growth has been uneven across types of elections and spenders under different legal regimes. This finding highlights the importance of disaggregating spenders, elections, and laws in order to explain IEs more fully. This article analyzes IEs in state gubernatorial and legislative elections from 2006 through 2018 across states with differing campaign finance laws and political contexts. It uses an original and detailed classification of spenders, along with data on IEs from the National Institute on Money in Politics, the Campaign Finance Institute's historical database of state campaign finance laws, and other sources. The legal variations on which the article focuses are the various states' laws limiting contributions to candidates and political parties. It concentrates on these because of an oft-stated expectation that removing contribution limits will sharply reduce the level of IEs. In addition to contribution limits, we also assess partisan competition as a primary explanation for the level of IEs in various states, and across the sectors of spenders. We find, using multi-variate analysis, that increased partisan competition (at both the candidate level and chamber level) is in most cases a significant driver of IEs. In contrast, the associations between IEs and contribution limits are inconsistent and generally not significant. Importantly for ongoing policy debates, ideological and issue-driven spending appears to have weak association (or none) with contribution limits. Therefore, if the recent increase in IEs is in fact a normative problem, the solution may be more elusive than once thought.
\end{abstract}

Keywords: elections, campaign finance, state politics, political parties, independent spending

Charles R. Hunt is an assistant professor of political science at Boise State University in Boise, Idaho, USA. Jaclyn J. Kettler is an assistant professor of political science at Boise State University in Boise, Idaho, USA. Michael J. Malbin is a professor of political science at the University at Albany, State University of New York, in Albany, New York, USA, and the director of the Campaign Finance Institute/National Institute on Money in Politics, in Helena, Montana, USA. Brendan Glavin is Senior Data Analyst at the Campaign Finance Institute/National Institute on Money in Politics, in Helena, Montana, USA. Keith E. Hamm is the Edwards Professor of Political Science at Rice University in Houston, Texas, USA.

(C) Charles R. Hunt et al., 2020; Published by Mary Ann Liebert, Inc. This Open Access article is distributed under the terms of the Creative Commons License (http://creativecommons .org/licenses/by/4.0), which permits unrestricted use, distribution, and reproduction in any medium, provided the original work is properly cited.

\section{INTRODUCTION}

$\mathbf{M}$ ORE THAN A DECADE has gone by since the Supreme Court decided that corporations have a constitutionally protected right to make unlimited independent expenditures (IEs). Most observers who followed elections had strong first impressions about how this decision would be likely to change U.S. politics. Many of those impressions were based on expectations of nearly direct relationships between the spending and contribution limits affected by this and successor cases and the behavior of political spenders. Some, for example, expected that for-profit corporations (and perhaps 
labor unions) would invest their treasury money heavily to affect (or threaten to affect) key elections. (See, for example, Obama 2010.) Others believed that Citizens United's application to non-profit corporations freed issue and ideological advocacy entities to attract potential donors away from the political parties, weakening the parties' relative power and feeding the forces that had been helping to polarize politics (La Raja and Schaffner 2015). These authors argued that removing the limits on contributions to and from the political parties would reverse the flow of money, bringing money back from independent spending organizations, thus reducing their absolute and relative power. And finally, others predicted that independent spending would dry up if the laws were rewritten to remove the limits on contributions to candidates (Institute for Free Speech 2017).

Implicit in these theories are a number of assumptions about independent spending that stand in need of reexamination. One such assumption is that the donors to most independent spending organizations would prefer to give directly to candidates or political parties. This assumption implies that contribution limits directly affect most current IEs. We argue that these assumptions are much too broad. Our knowledge about the role of interest groups and other political organizations in other settings leads us to expect that the political decisions of independent spenders are likely to vary with their goals, motivations, sources of funding, and other features. As a result, it seems highly unlikely that simply changing contribution limits would lead to consistent reactions for independent spenders of varying types, across political contexts.

In this article, we argue for the importance of differentiating among independent spenders, and then offer a potential framework for doing so. To make this argument we will first offer a basis for dividing the independent spenders into sectors, which we then operationalize by classifying all of the spenders appropriately. We then test the major contribution-limit-driven theories as explanations for each of the sectors by comparing their explanatory power to that of one of the more common alternatives used to explain independent spending before Citizens United, partisan competition.

As with campaign contribution limits, we do not expect partisan competition to have the same relationship to spending decisions across spending sec- tors. For example, organizations might use (or threaten to use) an IE to send signals rather than to secure a candidate's election or defeat. Others may use IEs instrumentally to elect candidates based on intra-party issue differences or ones without partisan connotations. Because spenders have differing levels of association and alignment with party goals, they should not all be expected to respond in the same way to partisan competition. However, measures of competition capture many of the changing contexts that independent spenders take into account when pursuing their political goals. Competition is, therefore, an important entryway into the key theoretical contribution of this article: that actors injecting money into the electoral process have differing motivations and goals shaped not just by legal changes like Citizens United, but also by changing political contexts.

To test these assertions, this article will look at IEs in state legislative and gubernatorial elections from 2006 through 2016. We use state elections rather than federal because it is impossible to test the explanatory power of variations in law by looking at only one legal jurisdiction. We acknowledge that different incentives may be at work on different jurisdictional levels, but will argue that the potential associations between contribution limits and IEs uncovered among the states will be applicable to the federal case. To evaluate sector-level differences in spending, we use an original dataset of statelevel independent spenders and their expenditures from the National Institute on Money in Politics $(\text { NIMP })^{1}$ paired with a database of historical state campaign finance laws from the Campaign Finance Institute (CFI). We employ an original, theoretically driven classification of the types of spenders based on a number of factors, including financial sources, party connections, and relationships with other spenders. To capture the cross-sectional effects of partisan competition and legal limits on contributions, we use a multivariate model that controls for state-level political institutions, state economies, and other exogenous forces that shape state elections.

In general, our results show that partisan competition tends to have more consistent effects across

\footnotetext{
${ }^{1}$ The National Institute on Money in Politics (NIMP) was known previously as the National Institute on Money in State Politics (NIMSP). Concurrently with the name change, the Campaign Finance Institute ceased free-standing operations and became a division within NIMP.
} 
multiple sectors than campaign contribution limits. More crucially, our classification framework reveals that different types of groups face differing incentives leading to different spending strategies. If, as many have argued, the explosion in independent spending has produced problems for our electoral process, fixing them requires taking these differences into account. The findings thus reinforce the importance of disaggregation in future analyses of campaign spending.

\section{SHORTCOMINGS OF PREVIOUS APPROACHES TO STUDYING IES}

As is well known, the Supreme Court's holding in Citizens United v. Federal Election Commission (2010) was that corporations have a constitutionally protected right to make unlimited independent expenditures (IEs) expressly advocating the election or defeat of candidates. A subsequent case, SpeechNow v. Federal Election Commission (2010), extended Citizens United to protect the right of individuals, corporations, labor unions, and other donors to make unlimited contributions to underwrite IEs. Subsequently, IEs in federal elections have skyrocketed (Malbin and Glavin 2020).

The changes in IEs have not been quite so dramatic in state elections but have been significant nonetheless (Stepleton 2018). Some states prohibited corporate spending before Citizens United while others did not. This variation in state law offers us a chance to make a first pass at asking whether removing the spending restriction corre- sponds uniformly to a growth in IEs. The following table is based on a descriptive comparison that uses a difference-in-differences approach. (The data on IEs, from the National Institute on Money in Politics, will be described more fully later.) For the comparison, we considered only the 15 states for which we have consistent IE data for every election since 2006. Of the 15,10 prohibited corporate expenditures before Citizens United; five did not. The 10 with prohibitions experienced an immediate policy change because of Citizens United and therefore were considered "treatment" states. The other five had no prohibitions before Citizens United and therefore did not experience a policy change because of the ruling. They were used as "control" states. We compared the rate of change in the level of IEs in each group of states between the pair of elections held in 2006-2008, before the decision, and 2014-2016. We used four-year time periods (two two-year election cycles) to include at least one gubernatorial election for each state. If removing corporate restrictions was the key driver of IE growth, we should see a greater rate of change in the treatment states. (Absolute spending levels are not relevant for this test; what matters is the comparative rate of change.)

Table 1 summarizes the results for all independent spenders in the two sets of states. The results are shown for gubernatorial and legislative elections combined and then separately.

The table shows that independent spending did, in fact, increase more in the treatment than control states. This finding is consistent with state-level research being done by Gilens, Patterson, and Haines

Table 1. Difference in Differences: Independent Expenditures in 2006-2008 Compared to 2014-2016

\begin{tabular}{|c|c|c|c|c|c|}
\hline & \# of states & $\begin{array}{l}\text { 2006-2008 } \\
\text { (\$ millions) }\end{array}$ & $\begin{array}{l}2014-2016 \\
\text { (\$ millions) }\end{array}$ & $\begin{array}{l}\text { Difference } \\
\text { (\$ millions) }\end{array}$ & Difference as a \% of 2006-2008 \\
\hline \multicolumn{6}{|c|}{ Gubernatorial and legislative elections combined } \\
\hline Treatment states & 10 & 66.0 & 192.6 & 126.6 & $192 \%$ \\
\hline Control states & 5 & 114.5 & 195.1 & 80.7 & $70 \%$ \\
\hline All states & 15 & 180.5 & 387.8 & 207.3 & $115 \%$ \\
\hline \multicolumn{6}{|c|}{ Gubernatorial elections only } \\
\hline Treatment states & 10 & 29.8 & 79.9 & 50.1 & $168 \%$ \\
\hline Control states & 5 & 53.5 & 19.1 & -34.4 & $-64 \%$ \\
\hline All states & 15 & 83.3 & 99.0 & 15.7 & $19 \%$ \\
\hline \multicolumn{6}{|c|}{ Legislative elections only } \\
\hline Treatment states & 10 & 36.2 & 112.7 & 76.5 & $211 \%$ \\
\hline Control states & 5 & 61.0 & 176.0 & 115.1 & $189 \%$ \\
\hline All states & 15 & 97.2 & 288.8 & 191.6 & $197 \%$ \\
\hline
\end{tabular}

Note: Full difference in difference results for all independent spending sectors appear in the Supplementary Appendix Tables A1.1, A1.2, and A1.3. Source: Derived from data supplied by the National Institute on Money in Politics. 
(2019) on the effect of Citizens United on the political power of business groups. ${ }^{2}$ However, separating the data for spending on gubernatorial and legislative elections shows that Citizens United had a much more powerful effect on the former. Moreover, when we replicate the analysis by sector we find even greater variation across IE sectors (see Supplementary Appendix Tables A1.1-3). In striking down many of the legal restrictions on IEs, Citizens United clearly opened a door, but not all groups and individuals were equally incentivized (or prepared) to walk through.

In this article, we argue that removing the corporate ban and contribution limits will work differently on different spenders. Before we make this argument, however, we first have to offer a basis for distinguishing among the spenders. Our approach is influenced heavily by previous scholars who have explored parallel differences in terms of a political organization's resources, political goals, and strategic contexts. For example, one team of researchers interviewed the political staffs of a diverse collection of federal interest groups and advocacy organizations to see how they expected to adapt to the Bipartisan Campaign Reform Act (BCRA) (Boatright et al. 2003, 46-48). They identified that the ways in which organizations expected to adapt varied with both internal factors (electoral goals, resources, and organizational constraints) and external ones (the legal, political, and communications contexts). Subsequently, Hansen et al. (2015) also noted the importance of organizational considerations in explaining why individuals rather than Fortune 500 corporations led the post-Citizens United growth in super PAC (political action committee) IEs in presidential elections, while corporations pursued alternate spending strategies. Our approach uses these observations to draw distinctions among IE organizations in state-level elections. Specifically, we use what we know about each spending organization's funding sources and goals as a basis both for defining the categories in this study and assigning organizations to them.

\section{DATA AND CATEGORIES}

Our framework leads us to expect that differences in IE spending will reflect differences among the organizations themselves as well as in their contexts. These considerations have informed our decisions for categorizing and analyzing the data for IEs in state elections. This section will describe our data collection and coding process and in doing so will describe the criteria used to sort the spenders into categories. It concludes with a description of the sectors (Table 2) that guide our subsequent analysis.

We began with data supplied by the National Institute on Money in Politics. Since the election of 2000, NIMP has been collecting the official records of contributions to candidates for state office, enhancing them with supplementary information, and presenting them in standardized formats for all 50 states. Starting with the election of 2006, NIMP began collecting records of IEs from all states requiring IE disclosure that had readily accessible IE records. NIMP collected records from 18 states in 2006. The number grew slowly in 2008 and 2010 and then spiked upward in 2012 as 11 more states added disclosure requirements after Citizens United. This article excludes a few states with data not adequate for our needs. States were included only if they could give us a consistent run of data either for the full 2006-2016 period of our study (15 states) or for the post-Citizens United cycles of 2012-2016 (another 11 states). ${ }^{3}$

In addition to the basic information about IEs provided by the states, NIMP assigns categories to most reporting committees. They include ones for political parties and labor and several for business that we collapsed into one. However, we needed to separate NIMP's single category for ideological/issue spenders for the ideas we were testing. We also discovered some entities in all categories with misleading names. This led us to review every entity that spent a total of $\$ 150,000$ or more cumulatively in 2006-2016 in legislative and gubernatorial elections. Organizations spending less than $\$ 150,000$ were not included in any of the data in this article. All told, there were 2,834 independent spenders in gubernatorial or legislative elections in

\footnotetext{
${ }^{2}$ We thank these authors for comments that led to corrections of an earlier version of Table 1.

${ }^{3}$ The 15 states with consistent 2006-2016 data were AZ, CA, CO, ID, MA, ME, MI, MN, MO, NC, OH, OK, TN, TX, and WA. The eleven additional states with consistent 2012-2016 data were AK, CT, IA, KY, MT, NH, RI, VA, WI, WV, and WY. The data from Florida and Arkansas did not have adequate candidate information to be included. Illinois was excluded because its contribution limits can be removed in a race under certain conditions, making it impossible to know the law that applied without looking at each race individually.
} 
our covered states. Of these, 1,730 met the threshold and were coded; 1,104 were not. The coded entities accounted for $97 \%$ of all IEs in these races.

Developing categories that meaningfully distinguish actors can be a challenge given the efforts some of them make to remain in the background. For example, the generically named committee "Building and Protecting a Strong California" was funded almost entirely by donations from firefighters, building trades, and correctional officers' unions. Given the funding source, it was therefore coded as "Labor." As this and many other examples make clear, there is no way to categorize many of the groups without digging beneath their names. By delving more deeply (where possible) into the groups' donors, as well as using contemporary news reports, we were able to identify their purposes and political orientations more extensively than previous scholarship.

Table 2 presents a full list of our group classifications and their descriptions. ${ }^{4}$ The following paragraphs explain the reasoning behind the categories.

Business and labor entities were fairly easy to identify once we dug below their names to get to their funding sources. ${ }^{5}$ It also was not difficult to identify state-level entities that were more or less parallel to the single-candidate super PACs prominent in presidential elections. These have been relatively unimportant in state elections so far. We include them in our descriptive tables but omit them from the multivariate analyses. Sorting becomes more complicated when considering the party, ideological, and issue sectors. Much of the analysis among scholars and in popular discourse compares party and non-party organizations. Formal party committees are usually easy to identify. The interesting questions arise when distinguishing less obvious party names from ideological and issue groups.

A recent working group report (Persily, Bauer, and Ginsberg 2018) points out that most party scholars fall into one of two camps. One camp defines parties almost solely in terms of the formal party organizations. Others (e.g., Bawn et al. 2012) see parties largely as networks defined by the ideological and issue activist organizations that make up their core supporters. As do other scholars, we keep the formal party sector distinct because we expect its members to have different goals from at least some of the other entities. Specifically, we expect parties to be interested in max-
Table 2. Independent Expenditure Group Sector CATEgories ANd DESCRIPTIONS

\begin{tabular}{|c|c|}
\hline Group type & Description \\
\hline Party & $\begin{array}{l}\text { Official state and local party committees and } \\
\text { legislative caucus campaign committees. }\end{array}$ \\
\hline $\begin{array}{l}\text { Party- } \\
\quad \text { affiliated }\end{array}$ & $\begin{array}{l}\text { This sector includes national organizations made } \\
\text { up of elected or party officials involved in } \\
\text { state/local races in more than one state. It also } \\
\text { includes organizations a substantial portion of } \\
\text { whose funding comes from a party or party- } \\
\text { affiliated organization. }\end{array}$ \\
\hline $\begin{array}{l}\text { Partisan } \\
\quad \text { coalitions }\end{array}$ & $\begin{array}{l}\text { Independent spending entities, most commonly } \\
\text { single-state, that are coalitions made up of (a) } \\
\text { traditionally pro-Democratic and left-leaning } \\
\text { organizations or (b) traditionally pro- } \\
\text { Republican and conservative organizations. } \\
\text { Many are active in more than one election but } \\
\text { invariably support candidates of only one } \\
\text { party. Some are active in only one contest. } \\
\text { The latter are distinguished from single- } \\
\text { election PACs by the fact that core support } \\
\text { comes from pre-existing left-leaning or right- } \\
\text { leaning entities and issue groups. }\end{array}$ \\
\hline Ideological & $\begin{array}{l}\text { Multi-issue organizations usually identified as } \\
\text { either liberal/progressive or conservative. They } \\
\text { may align tightly with one party, but their } \\
\text { identities and goals are distinct. They include } \\
\text { organizations that may typically support a } \\
\text { party's "mainstream" candidates, as well as } \\
\text { others trying to change one of the parties. }\end{array}$ \\
\hline Issue & $\begin{array}{l}\text { Organizations identified with a single cluster of } \\
\text { issues. These may support candidates of one } \\
\text { party or be bipartisan, but their core identities } \\
\text { are defined by the issue. }\end{array}$ \\
\hline Business & $\begin{array}{l}\text { Includes general business groups, trade } \\
\text { associations, business coalitions, for-profit } \\
\text { corporations, and entities largely funded by } \\
\text { business organizations. }\end{array}$ \\
\hline Labor & $\begin{array}{l}\text { Labor unions, coalitions, or other entities largely } \\
\text { funded by labor. }\end{array}$ \\
\hline $\begin{array}{l}\text { Single- } \\
\quad \text { election }\end{array}$ & $\begin{array}{l}\text { Entities supporting or opposing candidates in } \\
\text { only one election, with core support from } \\
\text { associates or supporters of candidates, not } \\
\text { from the partisan coalition sector above. }\end{array}$ \\
\hline
\end{tabular}

imizing the number of seats their candidates win in general elections. We also expect ideological and issue groups' behavior to be consistent with their having different first priorities from those of the parties, even though converging policy interests

${ }^{4}$ For anyone who wishes to see or use the codes, all of the entities and codes are available in Supplementary Appendix Table A3.1.

${ }^{5}$ This may prove more difficult in the future if donors and spenders channel more of their state-level independent expenditure (IE) money through intermediary sources that do not have to disclose their donors. For one discussion (among many) of such "dark money" and "gray money" organizational spending in federal elections, see Magleby and Goodliffe (2019, 111-23). 
Table 3. Independent Expenditures in State Legislative and Gubernatorial

Elections, 2006-2016, By Sector (\$ Millions)

Combined gubernatorial and legislative*

\begin{tabular}{|c|c|c|c|c|c|c|c|c|c|}
\hline \multirow[b]{2}{*}{ Years** } & \multicolumn{6}{|c|}{ Consistent 15 states } & \multicolumn{3}{|c|}{26 states } \\
\hline & 2006 & 2008 & 2010 & 2012 & 2014 & 2016 & 2012 & 2014 & 2016 \\
\hline Party & 23.0 & 14.0 & 27.4 & 12.9 & 17.8 & 17.5 & 13.5 & 20.0 & 18.7 \\
\hline Party-affiliated & 1.0 & 14.3 & 17.0 & 19.8 & 43.7 & 13.8 & 49.5 & 66.2 & 41.6 \\
\hline Partisan coalitions & 6.0 & 6.2 & 16.2 & 18.7 & 21.1 & 24.7 & 20.1 & 24.2 & 35.6 \\
\hline Ideological & 3.2 & 3.2 & 5.2 & 15.8 & 17.3 & 14.5 & 17.4 & 18.7 & 15.6 \\
\hline Issue & 18.6 & 5.5 & 7.9 & 9.8 & 21.5 & 51.5 & 14.2 & 33.8 & 56.8 \\
\hline Labor & 26.8 & 15.5 & 48.6 & 15.8 & 26.2 & 16.6 & 36.3 & 34.4 & 18.3 \\
\hline Business & 12.5 & 19.1 & 12.4 & 14.9 & 25.0 & 39.3 & 15.6 & 26.5 & 41.6 \\
\hline Single-election & 4.0 & 0.3 & 0.5 & 1.2 & 5.5 & 5.2 & 8.4 & 6.2 & 5.5 \\
\hline Other or not coded & 4.8 & 2.4 & 3.6 & 6.7 & 7.5 & 10.6 & 8.7 & 9.6 & 14.3 \\
\hline TOTAL & 99.9 & 80.6 & 138.5 & 183.3 & 185.5 & 193.7 & 183.3 & 239.7 & 247.9 \\
\hline
\end{tabular}

Source: Derived from data supplied by the National Institute on Money in Politics.

*Tables separating legislative and gubernatorial elections by sector may be found in Appendix Table A1.

***More states held their regular gubernatorial elections in 2006, 2010, and 2014 (shaded columns) than in 2008, 2012 , and 2016.

have led many to become more closely identified with a party than in less polarized times.

However, when we dig into NIMP's unified ideological/issue category we also see a handful of "non-party" organizations made up of elected officials or their direct surrogates. These include the Republican and Democratic Governors' Associations (RGA and DGA, respectively), along with the parallel entities for state legislators, attorneys general, and other public officials. Given their memberships and histories - the RGA was part of the Republican National Committee before BCRAwe thought it would be misleading to treat them as "non-party" in any functional sense. These organizations account for a substantial part of the wholemore than a quarter of all party and non-party IEs in 2012 and 2014. We separated these entities and described them as "Party-Affiliated." We expect them to behave in essentially the same way as formal party committees in state elections but with an ability to shift their attention among states as opportunities may dictate.

The rest of NIMP's ideological/issue sector was sorted into three groups. Issue and ideological groups were relatively easy to define using the definitions in Table 2. We separated them from each other because we suspect they might behave differently. Ideological entities, for example, are more likely to wage intraparty battles; the issue groups, in theory, should support a more heterodox collection of candidates. It is not obvious how this will connect to the variables we test in this article, but the separation ensures we do not lose information we may later find useful.
This left us with a final set that did not fit neatly into the other categories. These are coalitions of organizations whose members have their own identities. These "Partisan Coalitions" look somewhat like the parties described by network theorists but with a more transient presence. Because the coalition partners can vary widely from state to state, we did not have clear expectations for whether they would behave more like parties or like other issue groups and ideological groups. However, we shall see in the multivariate analysis that keeping them separate produced interesting results.

\section{Descriptive trends for IE group sectors}

By applying these sector groupings to the data for state elections, we find descriptive features that would not otherwise be apparent. While total IEs have increased, differences among the sectors have been notable. Table 3 shows the total IEs by sector. Six columns show the 15 states for which we have consistent data for all cycles. The three columns on the right show the same 15 states plus 11 others with consistent data after Citizens United. ${ }^{6}$ The appendix shows the same table for legislative and gubernatorial elections separately (Appendix Table A1). The variations in sectoral results in the appendix across the two types of elections give a hint of some differences we found in the multivariate analysis to follow.

\footnotetext{
${ }^{6}$ When reading the table, it is important to remember that roughly three times as many states held gubernatorial elections in 2006, 2010, and 2014 (shaded) as in 2008, 2012, and 2016.
} 
The overall growth in IEs is evident when one looks at comparable years across the six cycles. However, the patterns are remarkably inconsistent across the sectors of spenders and types of elections.

- Political parties spent roughly the same amount in legislative elections every year but declined substantially as a proportion of all legislative IEs.

- Party-Affiliated national organizations (primarily the Republican and Democratic Governors' Associations) more than picked up the slack for the state and local parties in gubernatorial elections. The parallel organizations for state legislative elections made fewer direct IEs but are among the important contributors to candidates and Partisan Coalitions.

- Partisan Coalitions, which include diverse sets of Issue, Ideological and Party-Affiliated organizations as their donors, have grown in importance over time in legislative elections. The sector declined in gubernatorial elections in 2016, as did the Party-Affiliated sector.

- Ideological and Issue organizations have been more important since Citizens United, but with each sector surging in different years.

- Labor spending in dollars has held relatively steady in legislative elections but declined as a proportion of the whole.

- Business IEs were fairly steady from 20062012 and then increased in 2014-2016.

- Finally, Single-Election entities have not yet become the significant players in state legislative or gubernatorial elections they have been in some federal contests. Because the numbers are so small, they will be excluded from the multivariate analysis to follow.

It is clear from the tables and capsule summaries that describing IEs solely in terms of their overall growth does not tell us enough. A single-minded focus on the aggregate total masks much of the variation needed to understand the differential impacts of legal and other contextual factors on spenders' decisions.

\section{EXPECTATIONS FOR THE MULTIVARIATE ANALYSIS}

We have suggested that differences in states' contribution limits regimes are unlikely by themselves to lead to behavioral changes evident among all types of spending entities equally. Goals, resources, and contexts will combine differently for different potential spenders. Testing this suspicion using a multivariate analysis that splits the samples by sector will help us determine how important these differences really are while controlling for a number of contextual state-level considerations outside of campaign finance laws.

As a major lens for uncovering the connections between contribution limits and IEs, we have focused on the presence or absence of limits on (1) contributions to candidates from all sources; (2) contributions from donors to political parties; and (3) contributions specifically from the parties to candidates. We will test these relationships while controlling not just for important differences among the spenders' sectors, but also for such crucial political contexts as state-level political competition. The law-related expectations to be tested are as follows:

- The baseline expectation is that restrictions on contributions to candidates should be associated with increased IEs in all sectors (Institute for Free Speech 2017).

- With regard to limits on party contributions, we test two different kinds of limits. The first is the presence or absence of legal limits on donations to the political parties. We expect that states with these limits in place will see greater constriction of parties' incomes, and therefore a lower level of IEs. We also expect this kind of limit to divert money toward others who make IEs. Like La Raja and Schaffner, we expect party limits to be associated with more spending by Party-Affiliated and PartisanCoalition groups. However, unlike La Raja and Schaffner, we do not necessarily expect to see a parallel relationship between these types of contribution limits and the level of spending by the Issue and Ideological sectors. The differing contribution sources, goals, and motivations behind the groups in these sectors should induce more nuanced spending behavior, particularly when group goals in many instances do not align with those of the parties.

- With respect to limits on contributions from the parties to candidates, we expect that states with these limits should see greater IEs by the parties and their closest affiliates when compared 
to states without such limits. As before, we do not expect such limits to affect Ideological, Issue, Business, or Labor sector IEs.

In addition to contribution limits, we will test whether higher levels of IEs across the states are associated with electoral competition, both at the race and chamber levels. We expect that for most IE groups, competition will lead to increased IEs in gubernatorial and legislative races. We also want to distinguish competition at the level of the individual legislative race from competition for control of a chamber. A battle for chamber control should reinforce the impact of competition for certain spenders, but not all sectors are likely to have the same stake in the fight for party control. Parties, PartyAffiliated, and most Partisan-Coalition organizations should have greater stakes in these outcomes. The effects on all other groups-particularly Issue and Ideological—should be more varied.

\section{METHODOLOGY}

There are two main sets of independent variables in this analysis: legal contribution limits and electoral competition. For campaign finance laws, we used the Campaign Finance Institute's Historical Database of State Campaign Finance Laws (CFI 2018). This database includes hundreds of variables for each state every two years since 1996, including the limits on contributions to candidates, PACs, and political parties. While the CFI database includes exact amounts for the limits in each state, we instead used a set of binary indicators for whether a state had contribution limits in place in a particular year. We do so because most states with contribution limits have relatively low limits, while only a few have limits greater than $\$ 10,000$. This essentially creates a bimodal distribution between states with contribution limits and states with no limits at all, making continuous or ordinal estimation of any effects of this variable unreliable. Even so, an ordinal specification of these variables (strict limits, lax limits, and no limits) produced highly robust results similar to those found with the binary indicators in our main analysis. ${ }^{7}$

First, we created a binary variable indicating whether a state limited contributions to candidates from individuals and/or PACs. This included 115 state-years out of the 133 in the data in our multivar- iate analyses $(85 \%)$. Second, we created a variable indicating whether a state limited contributions to candidates from the parties in a given year (100 state-years or $74 \%$ ). Finally, we created a binary variable for limits on contributions from individuals and/or PACs to the official party organizations (66 state-years or 49\%). The three binary indicators represent our primary independent variables for the laws that govern contributions. Though there is some overlap among state-years for these binary measures, there is enough variation such that we can be confident we are isolating the effects of each limit type. For example, while many states that limit contributions from individuals and PACs to candidates also do so for contributions from parties to candidates, 18 state-years do the former but not the latter (14\% of state-years with limits on contributions to candidates). Additionally, these two limit types are never included in the same model. This is done to avoid collinearity, to empirically isolate the cross-sectional effects of limits related to parties versus all others, and to acknowledge the theoretical effects each type of limit should produce for different sectors we have identified, particularly the parties and Party-Affiliated groups.

The second primary set of independent variables relates to partisan electoral competition at the race- and chamber-level. To measure competition in governors' races, we created an ordered scale based on race ratings produced by Larry J. Sabato's Crystal Ball newsletter in the summer prior to each election (Sabato n.d.). Sabato's ratings are based on judgment calls, but so are the decisions of independent spenders. The ratings are the most consistent pre-election assessments available for all of our years. These ratings were assigned before most independent spending in these races took place, thus avoiding potential problems of endogeneity. We coded the ordinal 0-4 variable according to the following rules: $0=$ no gubernatorial race, $1=$ safe race for one party or the other, $2=$ likely for one party or the other, $3=$ lean towards one party or the other, and $4=$ toss-up. We only report the models using Sabato's ratings, but our results are unchanged if we use actual election results.

Measuring legislative competition was more complicated, especially since our sample of states includes some with multi-member districts

\footnotetext{
${ }^{7}$ These results can be found in Supplementary Appendix Table A2.5.
} 
(MMDs). And since no nationwide experts consistently provide early ratings for state legislative seats, our only option was to use post-facto election results. For states with single-member districts (SMDs) and sub-districts with one seat/ post in MMDs (like Idaho and Washington), we considered races competitive when the winner received $55 \%$ or less of the top-two-candidate vote. It was more challenging to calculate competition for MMDs with plurality or bloc voting, in which voters cast their ballots for multiple candidates, and the top vote-getters win. To calculate competition in MMDs, we adopted Niemi et al.'s (1991) approach of creating pseudo-SMDs within the MMDs. ${ }^{8}$ We then divided the number of races that were competitive in each state-election by the total number of races in the state. This provided us with a state-level measure of the percentage of legislative races in an election that was competitive at the $55 \%$ threshold. ${ }^{9}$ We expect both the gubernatorial and legislative competition variables to positively predict independent spending activity.

Finally, in addition to the race-level competition, we also account for partisan competition for control of legislative chambers. Competition ratings at the state legislative chamber level are available from Louis Jacobson, but at inconsistent time intervals, and are not available for the 2006 election (Jacobson n.d.). Therefore, we instead use Hinchliffe and Lee's (2016) measure of the number of shifts in majority control of either legislative chamber in the state since 2000. The greater the number of recent shifts, the higher the likelihood of legitimate competition for chamber control, which we, therefore, expect to increase IEs in the state. The pre-election chamber ratings from 2008 to 2016 produced largely similar findings and can be found in the Supplementary Appendix (Table A2.1). Both measures avoid the potential problem of representing a post-treatment effect since they occur prior to most IEs, and are therefore not potentially endogenous with them.

To specify the impact of these limits properly, we must also control for other electoral factors that affect independent spending. While competition is a widely agreed driver of campaign spending and electoral activity, a number of other key controls ${ }^{10}$ used in previous studies are necessary. Among these are:

- The total number of legislative races happening in the state that year (because more legislative seats will increase total contributions - the denominator when we are measuring IEs as a percentage of the candidates' contributions);

- Squire's (2007) index of legislative chamber professionalism, since more full-time legislators may induce greater investment on the part of parties, donors, and interest groups;

- The presence of multi-member districts, which fundamentally complicates contribution and spending activity by including multiple candidates in a geographic area from the same party;

- The percentage of the state's population that is urban, to account for regional geographic and economic variations that could affect spending and contribution activity; and

- The statewide Gini index, which measures the extent of economic inequality in a state relative to others, and which could affect which types of sources of campaign funds and spending might have a greater impact.

Our models use these controls and our primary independent variables to predict the extent of independent spending in a given state-year. We do not,

\footnotetext{
${ }^{8}$ These pseudo-districts involve pairing the Democrat receiving the highest vote-share with the Republican receiving the fewest votes, and so on for the remaining candidates. In a two-member multi-member district (MMD), we then have two pseudodistricts each with a Democratic and Republican candidate. If the district is not fully contested, the candidate with the highest vote-share is treated as running in an uncontested race. By creating pseudo-pairs from individual candidates running in MMDs, we can evaluate them using the same criterion as single-member districts (SMDs) (whether the winner received $55 \%$ or less of the two-candidate vote).

${ }^{9}$ However, the results were also robust with models using a $60 \%$ threshold. They were also fairly robust using lagged measures of district-level vote share (pre-2006 election data from Klarner et al. (2013); results can be found in the Supplementary Appendix, Table A2.1), though we believe the contemporaneous measure is more appropriate despite endogeneity concerns for three main reasons: first, too many other state- and national-level factors change between election years to make lagged aggregate state competition a useful proxy for general levels of competitiveness in the state; it is, after all, this cycle's level of competition and chamber control that independent spenders are responding to, rather than last cycle, which also has a very different set of candidates running thanks to incumbent turnover and new challengers. Second, because we are aggregating competition in individual races up to a single state-level measure, this significantly smooths over district-level endogeneity issues. And third, because decennial redistricting occurs between the 2010 and 2012 cycles, the lagged 2012 state-level competition variable would be reflective of districts that no longer exist. ${ }^{10}$ The professionalism and Gini index measures were used from Hinchliffe and Lee (2016); percent urban was provided by Census estimates, and all other measures were calculated by the authors.
} 
however, use raw IE totals: instead, we divided the total dollar amount of IEs in each state by the total dollar amount of contributions made to all candidates in that state-year. ${ }^{11}$ We do this for two reasons. The first is that any state-level analysis must account for differences among the states, with the most important being the size and extent of spending and contribution activity in the states' elections. The amount of campaign money flowing through California, for example, obviously dwarves that of Rhode Island or Idaho. By using a denominator that is similarly responsive to between-state variation, we essentially standardize the dependent variable across all states. ${ }^{12}$

The second reason is more fundamental: because contribution totals vary between states in similar ways to state-level IEs, with both responsive to many of the same electoral and contextual conditions, the percentages let us capture the relative prominence of IEs in a given state's campaign finance ecosystem while accounting for betweenstate differences in total amounts spent and raised. The underlying assumption of theories connecting contribution limits and IEs is that many spenders would contribute rather than spend independently were it not for legal limits on contributions. It is, therefore, the proportion of spending to contributing in each state that most precisely captures the impact of cross-sectional variation in these limits. This proportion is also crucial for measuring the impact of partisan competition. While contributions are often higher in more competitive races and competitive states, a baseline level of contributions occurs in every campaign, even at the state and local levels. Donors, both large and small, contribute to candidates for reasons other than instrumentally affecting the outcome of the race. ${ }^{13}$ Independent spending, on the other hand, is almost uniformly done in races where the money can have the highest impact: competitive, winnable contests. Therefore, this relative presence of IEs, rather than raw dollar amounts, is the dependent variable of interest, and the proper concept for measuring the impact of limits and competition on IEs. ${ }^{14}$ To disaggregate effects by sector, we also computed additional dependent variables calculating the IEs from specific IE sectors as percentages of candidate contributions. ${ }^{15}$

Finally, to account for other foundational differences between states not captured by our control variables or the weighting of our dependent variable, we also employ random-effects generalized least squares (GLS) regression rather than standard ordinary least squares (OLS) regression. Random effects help us account for the fact that state-years from the same state are not fully independent of one another, even if they are fully (or at least very nearly fully) independent of observations for other states. Using random effects allows us to say with more confidence that variation in the dependent variable is not being caused by foundational differences among the states, but rather is accounted for primarily by the cross-sectional differences observed in the independent and dependent variables. While fixed effects would traditionally be the preferred method, laws governing limits on contributions rarely change within-state. Even over the full time period in this study (2006-2016), only three out of the 27 states implemented any kind of

\footnotetext{
${ }^{11}$ It is not possible to use only the money raised by candidates in targeted races because some states do not require the spenders to identify their targets.

${ }^{12}$ To partially account for the possibility that an unobservable variable affects contributions and skews the dependent variable, we also used state voting-eligible population in the denominator as a robustness check. The results (which can be found in Supplementary Appendix Table A2.4) are highly consistent with our in-text findings.

${ }^{13}$ Many small donors, for example, donate for reasons of ideological or expressive choice, or because they have a personal connection to a candidate (Francia et al. 2003; Schuessler 2000; Shieh and Pan 2010); many larger donors (usually special interest groups) donate for the purpose of access to safe incumbents once reelected (Kalla and Broockman 2016). As addressed earlier, no such similar pattern has been observed for IEs.

${ }^{14}$ It could be argued that competition would lead an independent spender to decide which races to engage, but the engagement could be in the form of a contribution as well as an IE. This is correct. The Republican and Democratic Governors' Associations typically made large contributions to candidates or parties in competitive elections with no contribution limits. Therefore, if we see a positive relationship between competition and IEs for these (or other) sets of groups, then the result is understating the importance of competition for the organization's overall spending decisions. From the point of view of our variable, however, the contributions made by these organizations makes up a small portion of the denominator (total contributions in the state) while being important portions of the IE numerator. However, when we look at our other principal independent variable of interest - the effect of the law-then the same issue does not exist. The claim that the law will have an effect is that organizations will shift money away from contributions toward IEs (which is what the RGA and DGA seem to do anecdotally). Using the variable we have chosen will underscore this shifting effect if there is one. If there is no effect (as there is not with most of our group sectors), then we can feel even more confident of the result.

${ }^{15}$ Descriptive statistics for our eight primary dependent variables, as well as our independent variables and controls, can be found in Appendix Table A2.
} 
Table 4. Effects on Independent Expenditures as Percent of Total Candidate Contributions, 2006-2016

\begin{tabular}{|c|c|c|c|c|c|c|c|c|}
\hline $\begin{array}{l}\text { Candidate contributic } \\
\text { Dependent variable }\end{array}$ & $\begin{array}{l}\text { Ilmits } \\
\text { All groups }\end{array}$ & Party orgs & $\begin{array}{c}\text { Party } \\
\text { affiliated }\end{array}$ & $\begin{array}{l}\text { Partisan } \\
\text { coalitions }\end{array}$ & Issue & Ideological & Business & Labor \\
\hline \multicolumn{9}{|l|}{ Contribution limits } \\
\hline $\begin{array}{l}\text { Contributions } \\
\text { to candidates }\end{array}$ & $0.18 *(0.09)$ & $0.04(0.04)$ & $0.05(0.04)$ & $0.04(0.03)$ & $0.01(0.01)$ & $0.00(0.01)$ & $0.01(0.01)$ & $0.02(0.01)$ \\
\hline \multicolumn{9}{|l|}{ Partisan competition } \\
\hline $\begin{array}{l}\text { Competition- } \\
\text { Governor's race }\end{array}$ & $0.02(0.03)$ & $-0.02 * *(0.01)$ & $0.05 * * *(0.02)$ & $-0.01(0.01)$ & $0.00(0.00)$ & $0.00(0.00)$ & $0.00(0.00)$ & $0.01 * * *(0.00)$ \\
\hline $\begin{array}{l}\text { Competition- } \\
\text { Legislative races }\end{array}$ & $1.31 * * *(0.36)$ & $0.30 * *(0.13)$ & $0.24(0.19)$ & $0.00(0.11)$ & $0.20 * * *(0.06)$ & $0.09 * * *(0.03)$ & $0.06(0.04)$ & $0.03(0.05)$ \\
\hline $\begin{array}{l}\text { Competition- } \\
\text { Control } \\
\text { of chamber }\end{array}$ & $0.06^{* * *}(0.02)$ & $0.01(0.01)$ & $0.03 * *(0.01)$ & $0.01(0.01)$ & $0.01 * * *(0.00)$ & $0.00(0.00)$ & $0.00(0.00)$ & $0.00(0.00)$ \\
\hline $\begin{array}{l}\text { R-Squared } \\
\text { (between-effects) }\end{array}$ & 0.64 & 0.31 & 0.7 & 0.25 & 0.62 & 0.25 & 0.36 & 0.54 \\
\hline$N$ & 130 & 130 & 130 & 130 & 130 & 130 & 130 & 130 \\
\hline
\end{tabular}

Note: Results found using generalized least squares regression with random effects by state.

$* p<0.1, * * p<0.05, * * * p<0.01$.

changes in these limits, thus making fixed-effects analysis imprecise and inappropriate as a specification strategy for identifying the effects of contribution limits on IEs.

Additionally, while many factors contribute to the nominal level of IEs in a state, many fewer would theoretically affect the relative presence of IEs compared to contributions. For this reason, our normalization of the dependent variable also helps account for these state-by-state differences. We therefore are not testing the explicit effect of adding or removing these types of legal campaign finance limits in a particular state or set of states in the fashion we were able to do in Table 1's difference-in-difference analysis. However, we believe that assessing cross-sectional differences between states is a crucial first step to the precise measurement of the potential impacts of legal limits on IEs, given the limitations of current data.

\section{ANALYSIS AND RESULTS}

In addition to the main random-effects model in which we assess the effects of contribution limits on all IEs as a percentage of all contributions, we also run seven additional models, identical save for the dependent variables; instead of all IEs, these models will predict Party IEs as a percent of all contributions, Party-Affiliated IEs, etc. Table 4 presents the results of the random-effects models of the effects of the presence of candidate contribution limits on IEs across states. The control variables discussed above are omitted in the main body of the paper for visual clarity but were in- cluded in the models that produced these results. Very few of the control variables produced significant coefficients, but full results are available in Appendix Tables A3 and A4.

First, Table 4 shows mixed results for the common hypothesis that the absence of contribution limits to candidates should be associated with much lower levels of independent spending. We see that while the contribution limits variable has mostly positive coefficients, it only reaches modest levels of statistical significance in the pooled models for overall IEs. In addition, in the various sectors of IEs-many of which have grown significantlythe substantive sizes of the coefficients are modest, and none reach significance. In most sectors, the relative presence of IEs seems almost completely unaffected by whether a state has contribution limits in place. Though these results are primarily crosssectional, it seems reasonable to assume that removing these limits in the states that have them would not be likely to significantly stem the level of independent spending taking place in those states. ${ }^{16}$

\footnotetext{
${ }^{16}$ We should note, however, that we did not test for IEs made by the single-election committees, which include those acting essentially as surrogates for the candidates. These were not major factors in the state elections we examined, appearing in only a select few of the state-years in our sample and therefore not easily or reliably specifiable in either the pooled models or separately in legislative and gubernatorial races. However, they are major factors in presidential elections, and we imagine them there to be directly related to the presence of contribution limits for candidates, combined with the weak rules governing the permissible relationships between the committees and the candidates they support.
} 
Our second set of results captures these same effects but tests the two types of party contribution limits rather than the limits on contributions to candidates. Table 5 presents a second set of models testing the effects of limits on contributions to and from parties on IEs. First, these results show that whether a state limits contributions to or from political parties does not have a statistically significant effect on the total level of independent expenditures relative to contributions except among some specific types of IE sectors. This suggests that party contribution limits are not associated, in the aggregate, with the level of total independent spending in an election. These limits also do not significantly affect Issue, Ideological, Business, or Labor groups' IEs compared to total contributions. In most cases for both sets of models, when the competition and contribution limits variables are included in the same model, the independent effects of contribution limits wash out in their significance.

However, separating IEs into these different spender sectors reveals a great deal about the apparently differing motivations and spending activities of these groups that would otherwise go unnoticed by aggregate analyses. For example, party limits do matter for how parties and those closest to the parties spend their money. We find unsurprisingly that the political parties decrease their IEs in states where there are limits on donations to the political parties. This is probably because they have less money available to spend compared to their counterparts in other, less-limited states. At the same time, Party-Affiliated groups significantly increase their IEs in states where there are limits on donations to parties. This makes sense because PartyAffiliated organizations like the Democratic or Republican Governors' Associations are essentially proxies for the party's interests. If the party organizations have less to spend, Party-Affiliated groups are likely to receive contributions that would have gone to the parties and to spend this would-be party money accordingly. These results at least partially support prior findings from La Raja and Schaffner (2015).

Yet surprisingly, limits on contributions to parties have more mixed-and in most cases, nosignificant effects on cross-state differences in IEs by Issue, Ideological, or Partisan Coalition groups. And surprisingly, the relationship for Partisan Coalitions finding was contrary to what we expected: If non-party organizations cannot contribute to the parties they normally support, one might expect that they would spend more, not less, as part of a coalitional party-allied independent spending group. However, the finding makes more sense when we take into account the formative nature of these groups. As addressed earlier, these groups are essentially coalitions of Party-Affiliated organizations like the DGA and RGA, Issue groups that tend to align with one party or the other, and Ideological groups that may have their own agendas but ally themselves with party-connected groups when goals are shared. These are essentially coalitions of the sort envisioned on a theoretical basis

Table 5. Effects on Independent Expenditures as Percent of Total Candidate Contributions, 2006-2016

\begin{tabular}{|c|c|c|c|c|c|c|c|c|}
\hline \multicolumn{9}{|c|}{ Party contribution limits } \\
\hline Dependent variable & All groups & Party orgs & $\begin{array}{c}\text { Party } \\
\text { affiliated }\end{array}$ & $\begin{array}{l}\text { Partisan } \\
\text { coalitions }\end{array}$ & Issue & Ideological & Business & Labor \\
\hline \multicolumn{9}{|l|}{ Contribution limits } \\
\hline $\begin{array}{l}\text { Contributions } \\
\text { from parties }\end{array}$ & $0.13(0.09)$ & $0.10 * * *(0.03)$ & $-0.07 * *(0.03)$ & $0.03(0.03)$ & $0.01(0.01)$ & $0.01(0.01)$ & $0.01(0.01)$ & $-0.01(0.01)$ \\
\hline $\begin{array}{l}\text { Contributions } \\
\text { to parties }\end{array}$ & $-0.06(0.08)$ & $-0.09 * * *(0.03)$ & $0.08 * * *(0.03)$ & $-0.02(0.03)$ & $-0.01(0.01)$ & $-0.01 *(0.01)$ & $-0.01(0.01)$ & $0.02 *(0.01)$ \\
\hline \multicolumn{9}{|l|}{ Partisan competition } \\
\hline $\begin{array}{l}\text { Competition- } \\
\text { Governor's race }\end{array}$ & $0.02(0.03)$ & $-0.02 * *(0.01)$ & $0.05 * * *(0.02)$ & $-0.01(0.01)$ & $0.00(0.00)$ & $0.00(0.00)$ & $0.00(0.00)$ & $0.01 * * *(0.00)$ \\
\hline $\begin{array}{l}\text { Competition- } \\
\text { Legislative races }\end{array}$ & $1.32 * * *(0.37)$ & $0.30 * *(0.12)$ & $0.36^{*}(0.19)$ & $0.01(0.11)$ & $0.20 * * *(0.06)$ & $0.08 * * *(0.03)$ & $0.06(0.04)$ & $0.04(0.05)$ \\
\hline $\begin{array}{l}\text { Competition- } \\
\text { Control } \\
\text { of chamber }\end{array}$ & $0.06 * * *(0.02)$ & $0.01(0.01)$ & $0.03 * *(0.01)$ & $0.01(0.01)$ & $0.01 * * *(0.00)$ & $0.00(0.00)$ & $0.00(0.00)$ & $0.00(0.00)$ \\
\hline $\begin{array}{l}\text { R-Squared } \\
\quad \text { (between-effects) }\end{array}$ & 0.61 & 0.61 & 0.77 & 0.23 & 0.61 & 0.36 & 0.38 & 0.59 \\
\hline$N$ & 130 & 130 & 130 & 130 & 130 & 130 & 130 & 130 \\
\hline
\end{tabular}

Note: Results found using generalized least squares regression with random effects by state.

$* p<0.1, * * p<0.05, * * * p<0.01$. 
by Bawn et al. (2012) and similar party theorists: policy-demanding groups with differing interests but united in their pursuit of electing a single party to satisfy their policy demands. As such, it is not always clear which of the three grouptypes-Party Affiliated, Issue, or Ideological-is at the head of the decision-making processes for any specific Partisan Coalition group. This, in turn, affects the overall impact. For example, Issue group spending is not affected by the presence of party contribution limits, while Ideological spending is. This leads us to believe that the impact of limits on the coalition groups is likely to vary with each group's composition. While we might have expected Partisan Coalition groups to behave more like Party-Affiliated organizations, the influence of Issue or Ideological groups will be greater in some Partisan Coalition groups than others.

When we look at state variance in regulations that limit donations from the political parties to candidates, we see little effect on most groups' IE spending except for the expected findings for Party and Party-Affiliated groups. Parties operating in states that limit their contributions to candidates tend to increase their IEs compared to those facing no such limits. The general lack of results for other less directly partisan sectors is not surprising.

While the effects of cross-state variations in campaign finance laws on IEs are at best inconclusive across sectors, the relationship between IEs and competition is clear and generally adheres to expectations. For nearly all sectors, the competition variables (which notably vary both between and within states over time) have the expected positive coefficients. Yet not all sectors reach significance with all measures of competition. For example, legislative competition - both at the race and chamber levels - appears to be a significant motivator for independent spending for Issue groups, while gubernatorial competition is more motivating for Labor organizations. Other sectors have different mixes of significance; and others still, like Partisan Coalition groups and Business groups, are not significant at all. This variation, we believe, points even further to the necessity of differentiation to get at the root issues. Clearly, spenders' decisions about when to spend and when not to spend depend not just on the level of electoral competition, but also on the spenders' funding sources and their ultimate goals in the electoral process. These findings support the results in previous research (e.g., Hamm et al.
2014), and indicate that groups are strategic in their IEs based on levels of partisan competition. They rationally increase their spending on IEs when the money may affect the outcome, whether in an individual race or in the battle for majority control. In total, variables denoting higher partisan competition appear to outstrip contribution limits in driving up independent expenditure activity in the states.

Moreover, these findings hold even when splitting legislative and gubernatorial IEs and competitiveness measures into separate models. The results of these tests, which can be found in the Supplementary Appendix (Tables A2.6 and A2.7), show that the predictive power of contribution limits remains inconsistent. Partisan competition, however, appears more consistently to be a predictor of increased IEs. This may indicate that gubernatorial and legislative IEs should be considered separately rather than together, particularly since doing so produced diverging results in the difference-indifference test introduced earlier in Table 1 . These changes were particularly notable when, as in the multivariate analysis, we separated IEs into different sectors. Regardless of the specification, the effects of partisan competition, as well as other variables, continue to depend in part on the spender sector, validating our approach of separating sectors into separate models to capture their differing objectives and funding sources. But notably, partisan competition in both appears to increase the involvement of independent spenders far more consistently than contribution limits.

One potential limitation in these findings must be acknowledged before we leave them. They are not, strictly speaking, causal. Our data cannot settle whether adding or removing contribution limits in a particular state would directly lead to changes in IEs. But this admitted limitation does not negate what the article has found. It is not necessary to explain the causes of IEs affirmatively to make an important contribution to ongoing policy debates. Whatever one may conclude eventually about causality, these findings undermine the central claim of those who would end contribution limits in the name of reducing IEs. This research finds no clear association between party contribution limits and IEs at the same time as it finds a clear association between IEs and competition. The relationship between IEs and competition does not lead us toward obvious policy conclusions. However, comparing 
the one set of clear relationships (between competition and IEs) to the absent ones (between party limits and IEs) should be enough to shift the burden of causal proof to those who say they expect to hack away at IEs by removing the limits on contributions.

\section{CONCLUSION}

We began this article by arguing for the importance of disaggregating expenditures both by types of election and spenders. We presented an updated theory regarding the differing funding, goals, motivations, and contexts of IE sectors, and then applied this theory empirically by categorizing the entities responsible for $97 \%$ of the IEs in the states for which usable data are available. Separating IEs into sectors in our multivariate analysis showed that the actions and considerations of IE groups are more nuanced than previous work has assumed. The analysis points us away from seeing contribution limits as a primary explanation for IEs, particularly when we look at the spending sectors separately. The sectoral results remind us that different spenders will place their priorities on different goals, some of which are better realized through IEs than contributions. They also tell us that laws are only one set of considerations political actors take into consideration when they make strategic spending decisions. By using a broad crosssection of states, laws, and levels of competition over an extended period of time, it is clear that partisan competition is an unavoidable consideration for many (though notably, not all) sector groups, and that these effects combine with organizational interests and motivations to outstrip the effects of contribution limits in stimulating IEs when comparing across states. In considering the totality of these results, it appears that if the recent increase in IEs is a normative problem, the solution may be more elusive than previous scholars have thought.

Readers whose main interests lie with presidential and congressional elections might wonder whether these findings apply to the federal context. We see no reason to doubt that similar relationships would apply, although some of the actors are different. IEs coming from the Ideological, Issue, Labor, and Business sectors seem to be driven by similar concerns on both levels. Indeed, many of the same organizations spend in both. (For a discussion of national-level Issue and Ideological IEs using a sim- ilar theoretical framework, see Boatright, Malbin, and Glavin 2016). Two sets of actors may behave differently. First, the federal super PACs and nonprofit entities closely related to the four congressional party leaders so far have behaved much the same as the Party-Affiliated entities in this study. However, the Party-Affiliated organizations in our study are making strategic decisions across many states while the federal entities are associated with only one set of party leaders each. As a result, removing all limits on contributions going into the federal party committees could well lead major donors to prefer giving directly to the formal parties over these entities. Second, as noted earlier in this article, spending entities that function as surrogates for individual candidates have not yet caught on in the states. Whether they will do so remains an open question. Their large role in some recent presidential elections (as well as their occasional role in congressional elections) rests in part on the Federal Election Commission's regulatory and enforcement inaction. State regulators may or may not be so passive.

But even these differences underscore the main theme: the importance of applying goal-oriented strategic thinking to independent spending entities and their major donors. Surrogate entities (whether for candidates or party leaders) will closely mirror the goals of their principals, even if the principals' identities are not spelled out in legal documents. Other independent spenders (and their donors) will have their own goals and act accordingly. This will be true at all levels of government.

\section{SUPPLEMENTARY MATERIAL}

Supplementary Appendix

\section{REFERENCES}

Bawn, Kathleen, Martin Cohen, David Karol, Seth Masket, Hans Noel, and John Zaller. 2012. "A Theory of Political Parties: Group Policy Demands and Nominations in American Politics." Perspectives on Politics 10(3): 571-597.

Boatright, Robert G., Michael J. Malbin, and Brendan Glavin. 2016. "Independent Expenditures in Congressional Primaries after Citizens United: Implications for Interest Groups, Incumbents, and Political Parties." Interest Groups \& Advocacy 5(1): 1-22 (March). 
Boatright, Robert G., Michael J. Malbin, Mark J. Rozell, and Clyde Wilcox. 2003. "BCRA's Impact on Interest Groups and Advocacy Organizations." Chap. 3 in Life after Reform: When the Bipartisan Campaign Reform Act Meets Politics, ed. Michael J. Malbin. Lanham MD: Rowman and Littlefield.

Campaign Finance Institute (CFI). 2018. "Introducing CFI's Groundbreaking Database of State Campaign Finance Laws." Press Release. April 3. <http://cfinst.org/Press/ PReleases/18-04-03/CFI\%E2\%80\%99s_Groundbreaking Database_Of_State_Campaign_Finance_Laws.aspx $>$ (accessed August 8, 2018>.

Citizens United v. Federal Election Commission. 558 U.S. 310 (2010).

Francia, Peter L., John C. Green, Paul S. Herrnson, Lynda W. Powell, and Clyde Wilcox. 2003. The Financiers of Congressional Elections. New York, NY: Columbia University Press.

Gilens, Martin, Shawn Patterson, and Pavielle Haines. 2019. "Changing the Rules: Independent Expenditures and Public Policy in the U.S. States." Paper presented at the Annual Meeting of the American Political Science Association, August 29-September 1.

Hamm, Keith E., Michael J. Malbin, Jaclyn J. Kettler, and Brendan Glavin. 2014. "Independent Spending in State Elections, 2006-2010: Vertically Networked Political Parties Were the Real Story, Not Business.” The Forum: A Journal of Applied Research in Contemporary Politics 12(3): 305328.

Hansen, Wendy L., Michael S. Rocca and Brittany Leigh Ortiz. 2015. "The Effects of on Corporate Spending in the 2012 Presidential Election.” Journal of Politics 77(2): 535.

Hinchliffe, Kelsey L. and Frances E. Lee. 2016. "Party Competition and Conflict in State Legislatures." State Politics and Policy Quarterly 16(2): 172-197.

Institute for Free Speech. 2017. Policy Primer-Campaign Contribution Limits: A Cap on Free Speech. Alexandria VA. <https://www.ifs.org/wp-content/uploads/2014/07/ 2014-10-22_IFS-Policy-Primer_Contribution-Limits.pdf> (accessed August 21, 2018).

Jacobson, Louis. n.d. "Louis Jacobson, Contributor." Governing. Jacobson's articles available at https://www.governing .com/authors/Louis-Jacobson.html (accessed August 6, 2020).

Kalla, J.L. and Broockman, D.E., 2016. "Campaign Contributions Facilitate Access to Congressional Officials: A Randomized Field Experiment." American Journal of Political Science 60(3): 545-558.

Klarner, Carl, William D. Berry, Thomas M. Carsey, Malcolm Jewell, Richard Niemi, Lynda Powell, and James Snyder. 2013. "State Legislative Election Returns (1967-2010)." Inter-university Consortium for Political and Social Research [distributor]. <https://www.icpsr.umich.edu/web/ ICPSR/studies/34297/versions/V1>.

La Raja, Raymond J. and Brian F. Schaffner. 2015. Campaign Finance and Political Polarization: When Purists Prevail. Ann Arbor, MI: University of Michigan Press.

Magleby, David B. 2014. "Classifying Super PACs." In State of the Parties, eds. Daniel Coffey, David Cohen, and John Green, 7th ed. Lanham, MD: Rowman and Littlefield.
Magleby, David B. and Jay Goodliffe. 2019. "Interest Groups in the 2016 Election." In Financing the 2016 Election, eds. D. Magleby and J. Goodliffe. Washington, DC: Brookings Institution Press.

Malbin, Michael J. and Brendan Glavin. 2020. CFI's Guide to Money in Federal Elections: Essays and Tables Covering the Elections of 1974-2018. Washington, DC, and Helena MT: Campaign Finance Institute. January. Available at $<$ http://cfinst.org/pdf/federal/2018Report/CFIGuide_Money inFederalElections_2018upd.pdf> (accessed August 6, 2020).

Obama, Barack. 2010. "Remarks by the President on the DISCLOSE Act." July 26. <https://obamawhitehouse.archives .gov/the-press-office/remarks-president-disclose-act> (accessed August 20, 2018).

Niemi, Richard G., Simon Jackman, and Laura R. Winsky. 1991. "Candidacies and Competitiveness in Multi-Member Districts.” Legislative Studies Quarterly 16(1): 91-109.

Persily, Nathaniel, Robert F. Bauer, and Benjamin L. Ginsberg. 2018. Campaign Finance in the United States: Assessing an Era of Fundamental Change. Washington, DC: Bipartisan Policy Center. Available at <https://bipartisanpolicy.org/ wp-content/uploads/2019/03/BPC-Democracy-CampaignFinance-in-the-United-States.pdf $>$ (accessed August 8, 2018).

Sabato, Larry J. n.d. Sabato's Crystal Ball. University of Virginia Center for Politics. http://centerforpolitics.org/crystalball/ archives (accessed August 6, 2020).

Schuessler, A.A., 2000. A Logic of Expressive Choice. Princeton, NJ: Princeton University Press.

Shieh, S. and Pan, W.H., 2010. "Individual Campaign Contributions in a Downsian Model: Expressive and Instrumental Motives." Public Choice 145(3-4): 405-416.

SpeechNow.org v. Federal Election Commission. 599 F.3d 686 (D.C. Cir. 2010), cert. denied sub nom, Keating v. FEC, 131 S. Ct. 553 (2010).

Squire, Peverill. 2007. "Measuring State Legislative Professionalism: The Squire Index Revisited." State Politics and Policy Quarterly 7(2): 211-227.

Stepleton, J. T. 2018. "Independent Spending Overview, 2015 and 2016." National Institute on Money in State Politics. February 14. Available at <https://www.followthemoney .org/research/institute-reports/independent-spending-overview2015-and-2016> (accessed August 8, 2018).

Address correspondence to: Charles R. Hunt School of Public Service Political Science

Boise State University Boise, ID 83725 USA

E-mail: charleshunt@boisestate.edu

Received for publication March 30, 2019; received in revised form June 15, 2020; accepted June 27, 2020; published online August 27, 2020.

(Appendix follows $\rightarrow$ ) 


\section{Appendix}

Appendix Table A1. Independent Expenditures in State Legislative and Gubernatorial ELECTIONS, 2006-2016, By SECTOR (\$ MILLIONS)

Gubernatorial only

\begin{tabular}{|c|c|c|c|c|c|c|c|c|c|}
\hline \multirow[b]{2}{*}{ Years* } & \multicolumn{6}{|c|}{ Consistent 15 states } & \multicolumn{3}{|c|}{26 states } \\
\hline & 2006 & 2008 & 2010 & 2012 & 2014 & 2016 & 2012 & 2014 & 2016 \\
\hline Party & 9.7 & 1.0 & 13.3 & 0.0 & 2.4 & 1.8 & 0.0 & 2.6 & 1.9 \\
\hline Party-affiliated & 0.3 & 12.3 & 13.8 & 17.8 & 38.1 & 7.5 & 41.0 & 59.6 & 33.3 \\
\hline Partisan coalitions & 4.0 & 0.3 & 8.9 & 9.3 & 11 & 0.9 & 9.3 & 11.4 & 5.4 \\
\hline Ideological & 1.8 & 0.0 & 3.1 & 0.5 & 2.3 & 1.3 & 1.4 & 3.8 & 1.8 \\
\hline Issue & 14 & 1.0 & 5.1 & 1.5 & 6.4 & 6.0 & 3.0 & 16.9 & 8.4 \\
\hline Labor & 19.8 & 6.3 & 39.0 & 0.9 & 9.2 & 0.7 & 7.9 & 15.1 & 1.7 \\
\hline Business & 1.0 & 7.3 & 1.8 & 0.1 & 1.2 & 0.5 & 0.1 & 1.3 & 0.5 \\
\hline Single-election & 4.0 & 0.0 & 0.0 & 0.0 & 2.4 & 1.3 & 7.2 & 3.0 & 1.4 \\
\hline Other or not coded & 0.3 & 0.3 & 0.4 & 0.3 & 1.1 & 0.4 & 0.8 & 1.9 & 0.7 \\
\hline Total & 54.8 & 28.5 & 85.3 & 30.5 & 74.2 & 20.4 & 70.8 & 115.7 & 55.2 \\
\hline
\end{tabular}

Legislative only

\begin{tabular}{|c|c|c|c|c|c|c|c|c|c|}
\hline \multirow[b]{2}{*}{ Years* } & \multicolumn{6}{|c|}{ Consistent 15 states } & \multicolumn{3}{|c|}{26 states } \\
\hline & 2006 & 2008 & 2010 & 2012 & 2014 & 2016 & 2012 & 2014 & 2016 \\
\hline Party & 13.4 & 13.0 & 14.0 & 12.9 & 15.4 & 15.7 & 13.5 & 17.3 & 16.8 \\
\hline Party-affiliated & 0.8 & 2.0 & 3.2 & 1.9 & 5.5 & 6.4 & 8.4 & 6.6 & 8.3 \\
\hline Partisan coalitions & 2.0 & 6.0 & 7.3 & 9.3 & 10.1 & 23.7 & 10.7 & 12.8 & 30.2 \\
\hline Ideological & 1.4 & 3.2 & 2.1 & 15.3 & 15.0 & 13.2 & 16.0 & 15.0 & 13.8 \\
\hline Issue & 4.6 & 4.5 & 2.9 & 8.3 & 15.1 & 45.5 & 11.3 & 16.9 & 48.4 \\
\hline Labor & 7.0 & 9.2 & 9.6 & 14.9 & 17.0 & 15.9 & 28.4 & 19.3 & 16.6 \\
\hline Business & 11.5 & 11.8 & 10.4 & 14.8 & 23.8 & 38.8 & 15.5 & 25.2 & 41.1 \\
\hline Single-election & 0.0 & 0.3 & 0.5 & 1.2 & 3.1 & 3.9 & 1.2 & 3.1 & 4.1 \\
\hline Other or not coded & 4.5 & 2.3 & 3.2 & 6.3 & 6.4 & 10.2 & 7.4 & 7.7 & 13.6 \\
\hline Total & 45.1 & 52.1 & 53.1 & 84.9 & 111.3 & 173.3 & 112.4 & 123.9 & 192.8 \\
\hline
\end{tabular}

*More states held gubernatorial elections in 2006, 2010, and 2014 (shaded columns) than in 2008, 2012, and 2016.

Appendix Table A2. Descriptive Statistics for Key Variables (Model Cases Only)

\begin{tabular}{|c|c|c|c|c|}
\hline Variable & Mean & Std. deviation & Min. & Max. \\
\hline All IEs* & 0.2 & 0.3 & 0.0 & 1.6 \\
\hline Party IEs* & 0.0 & 0.1 & 0 & 0.7 \\
\hline Party-affiliated IEs* & 0.1 & 0.1 & 0 & 1.0 \\
\hline Party allied IEs* & 0.0 & 0.1 & 0 & 0.6 \\
\hline Issue group IEs* & 0.0 & 0.0 & 0 & 0.3 \\
\hline Ideological group IEs* & 0.0 & 0.0 & 0 & 0.2 \\
\hline Business group IEs* & 0.0 & 0.0 & 0 & 0.2 \\
\hline Labor group IEs* & 0.0 & 0.0 & 0 & 0.3 \\
\hline Limits-Contributions from parties & 0.7 & 0.4 & 0 & 1 \\
\hline Limits-Contributions to parties & 0.5 & 0.5 & 0 & 1 \\
\hline Limits-Contributions to candidates & 0.8 & 0.4 & 0 & 1 \\
\hline Total legislative races & 139 & 58 & 50 & 424 \\
\hline Recent shifts/chamber majority & 0.9 & 1.0 & 0 & 3 \\
\hline Gubernatorial competition & 1.3 & 0.8 & 0 & 3 \\
\hline Legislative competition & 0.2 & 0.1 & 0 & 0.4 \\
\hline Gubernatorial power score & 3.5 & 0.4 & 2.6 & 4.3 \\
\hline State $\%$ urban & 73.2 & 13.6 & 38.7 & 95.0 \\
\hline Gini index & 0.6 & 0.0 & 0.5 & 0.8 \\
\hline Chamber professionalism & 0.2 & 0.1 & 0 & 0.6 \\
\hline Multi-member districts & 0.2 & 0.4 & 0 & 1 \\
\hline
\end{tabular}

*Divided by total contributions to candidates; IE, independent expenditures. 


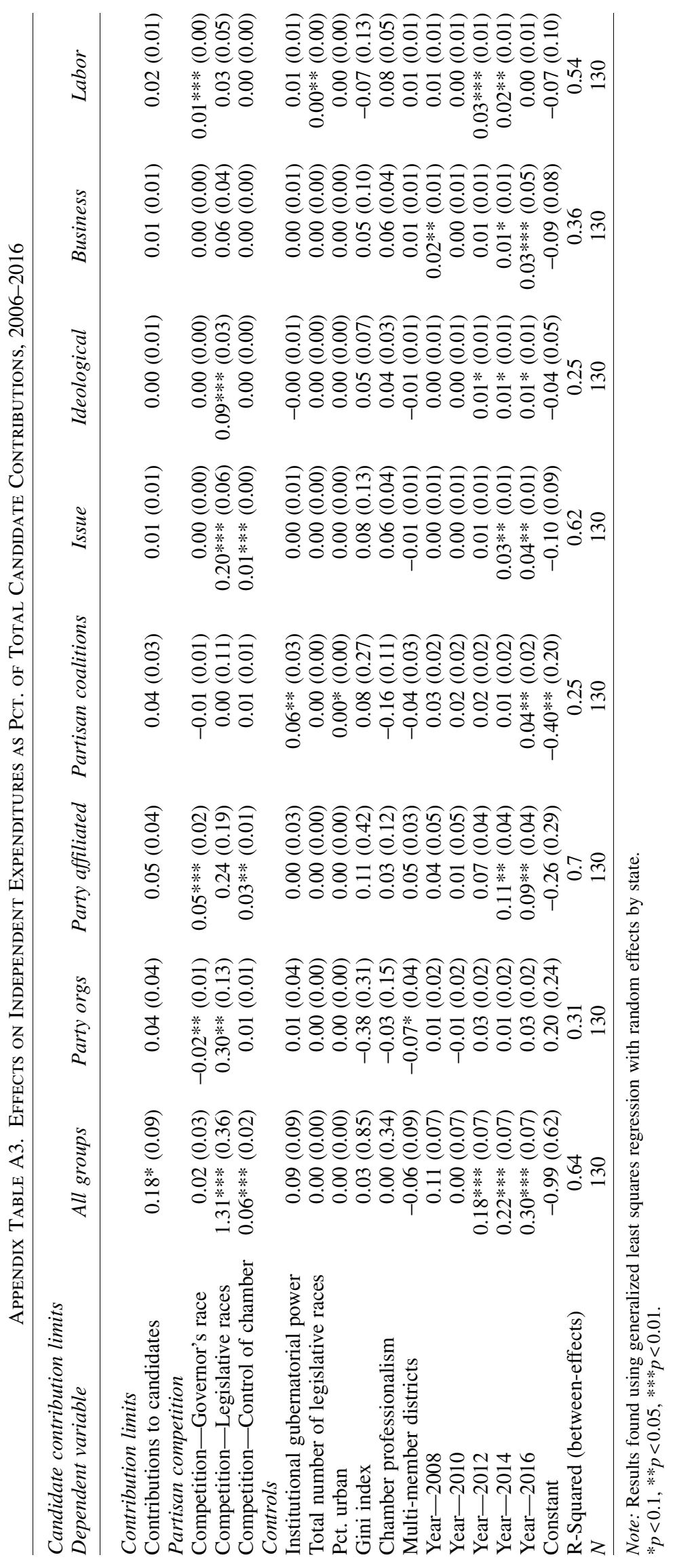




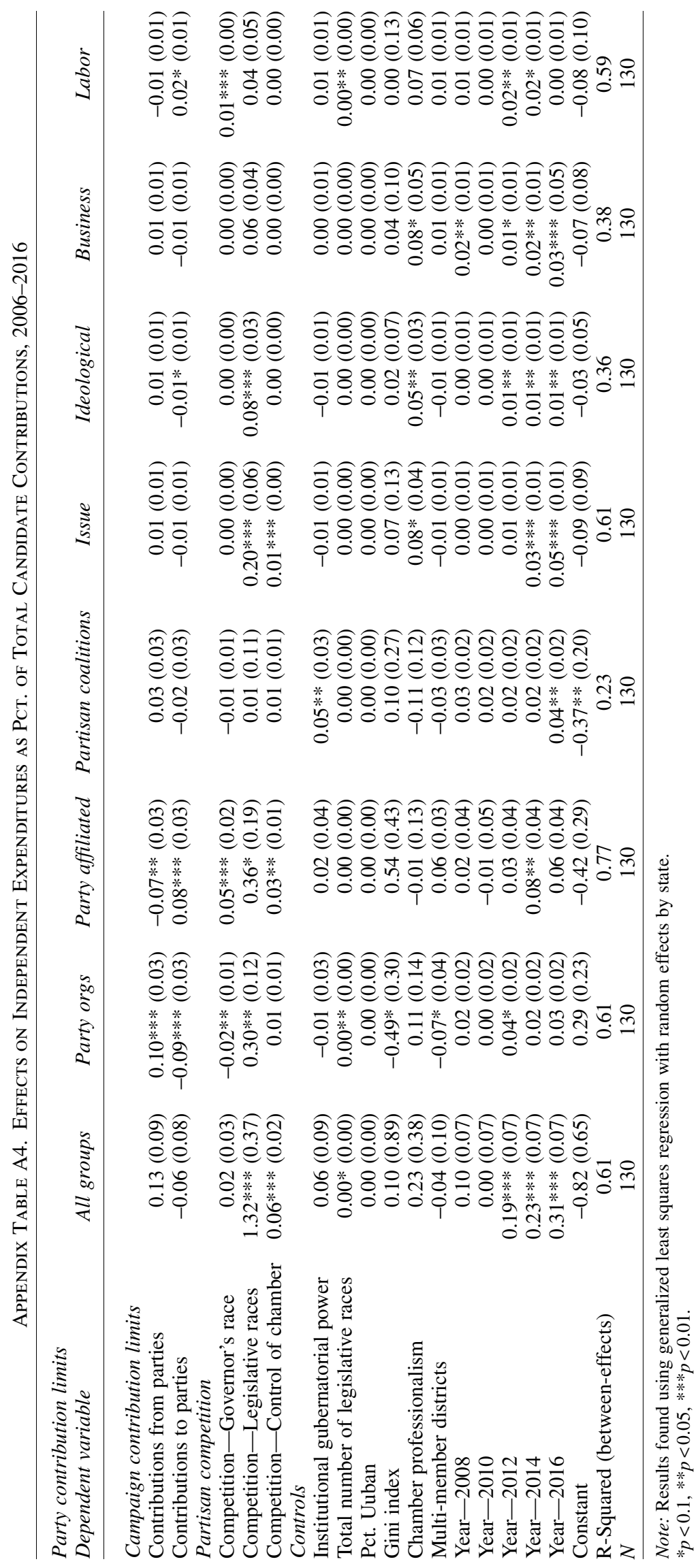

